[14] Ob unifikatsii mikrobiologicheskih (bakteriologicheskih) metodov issledovaniya, primenyaemih v kliniko-diagnosticheskih laboratoriyah lechebno-profilakticheskih uchrezhdeniy (1985). MZ SSSR, No. 535. Available at: http://www.alppp.ru/law/ zdravoohranenie--fizicheskaja-kultura-i-sport--turizm/zdravoohranenie/64/prikaz-minzdrava-sssr-ot-22-04-1985--535.html

[15] Baron, E. J., Miller, J. M., Weinstein, M. P., Richter, S. S., Gilligan, P. H., Thomson, R. B. et. al. (2013). A Guide to Utilization of the Microbiology Laboratory for Diagnosis of Infectious Diseases: 2013 Recommendations by the Infectious Diseases Society of America (IDSA) and the American Society for Microbiology (ASM)a. Clinical Infectious Diseases, 57 (4), e22-e121. doi: http://oi.org/10.1093/cid/cit278

[16] Pro zatverdzhennya metodichnykh vkazivok "Vyznachennya chuvstvitelnosti mikroorganizmov do antibacterialnykh preperativ” (2007). MOZ Ukraine, No. 167. 05.04.2007. Available at: http://search.ligazakon.ua/1_doc2.nsf/link1/MOZ6809.html

[17] Kozlovz, N. S., Barantchevich, N. E., Ivanova, L. V. et. al. (2015). Chuvstvitelnost k antibacterialnym preperatam staphilokokov, tchirkuliruushchikh v mnogoprophilnom statchionare. Problemy meditchinskoy mikologii, 17 (4), 58-62.

\title{
DYNAMICS OF FUNCTIONAL CONDITION AND QUALITY OF LIFE IN PATIENTS WITH ASTHMA-COPD OVERLAP AND CONCOMITANT ARTERIAL HYPERTENSION AGAINST THE BACKGROUND OF COMPLEX THERAPY
}

\author{
Maryna Kochuieva ${ }^{1}$ \\ kochuevamarina@gmail.com \\ Hanna Tymchenko ${ }^{1}$ \\ hanna.zaprovalna@gmail.com \\ Ivan Hrek ${ }^{1}$ \\ grek.ivan.md@gmail.com \\ Yulia Zaikina ${ }^{1}$ \\ julia.ua.h@gmail.com \\ ${ }^{1}$ Department of Phthisiology, Pulmonology and Family Medicine \\ Kharkiv Medical Academy of Postgraduate Education \\ 58 Amosova str., Kharkiv, Ukraine, 61176
}

\footnotetext{
Abstract

Patients with ACO have significant poorer health-related quality of life and more severe functional limitations compared to asthma and COPD alone. Most commonly, chronic respiratory disease is associated with cardiovascular disease, such as arterial hypertension. However, the impact of concomitant cardiac diseases on the quality of life and functional status of patients with ACO remains poorly understood.

The aim of the work was to study dynamics of functional condition and quality of life in with ACO and concomitant AH against the background of complex therapy.

Materials and methods. We selected for participating in the study 100 patients with ACO and concomitant AH. Examination of the patients included: clinical methods, spirometry, and questinaries - mMRS, CAT, SGRQ, performing 6MWT.

Results. After 16 weeks of treatment there were no changes in lung functional status in patients on standard treatment, at the same time, in group of patients who had an active rehabilitation program, there was a significant improvement in the bronchial response to the action of bronchodilators, although other indicators of the functional status of the lungs didn't show significant changes. Patients
} 
who additionally used an active rehabilitation program had a significant improvement in clinical symptoms, shortness of breath, and quality of life according to CAT, mMRC, and SGRQ scores, respectively. There was also a significant increase in distance during the $6 \mathrm{MWT}$ in this group of patients.

Conclusions. Conducting an active rehabilitation program (physical rehabilitation in combination with an educational program and self-management) in group of patients with ACO and concomitant AH, who are on standard medical treatment, significantly improves the bronchial response to the action of bronchodilators, decreases clinical manifestations, shortness of breath and improve quality of life and exercise tolerance, according to CAT, mMRC, SGRQ and 6MWT questionnaires, respectively.

Keywords: asthma-COPD overlap, arterial hypertension, functional status, quality of life, rahabilitation.

DOI: $10.21303 / 2504-5679.2020 .001135$

\section{Introduction}

Chronic respiratory diseases are a serious problem of modern medicine, due to their widespread prevalence, high rates of mortality; also, it is a leading cause of disability and medical costs [1]. The most common respiratory diseases are chronic obstructive pulmonary disease (COPD) and asthma [2].

However, a combination of symptoms of asthma and COPD is observed in many of patients, especially those over 40 years of age with a history of concomitant smoking. According to various authors, the proportion of such patients ranges from 15 to $55 \%$ [3]. For clinical practice, in 2014 Global Initiative for Asthma (GINA) and Global Initiative for COPD (GOLD) guideline [4] suggested the syndrome approach and the term asthma-COPD overlap syndrome (ACOS), later changed to Asthma-COPD Overlap (ACO) in GINA 2017 Recommendations [3].

Most commonly, chronic respiratory disease is associated with cardiovascular disease, such as arterial hypertension (AH). According to the literature, the incidence of combination of AH with chronic respiratory disease ranges from 4 to $27 \%$ [5].

ACO patients have significant respiratory symptoms, poor quality of life, frequent exacerbations that lead to more frequent medical visits, comorbidities, and increasing doses of medication compared to asthma and COPD [6, 7]. Studies have shown that patients with ACO have poorer health-related quality of life than patients with asthma or COPD alone [8].

Some studies have shown that patients with ACO have functional limitations based on such functional tests as the 6-minute walk test (6MWT) and BODE index, which in turn have an important prognostic relationship with mortality and exacerbation rates [9].

However, these studies excluded patients with comorbid conditions, so the impact of concomitant cardiac diseases on the quality of life and functional status of patients with ACO remains poorly understood.

Aim of the research - to investigate dynamics of functional condition and quality of life in with ACO and concomitant AH against the background of complex therapy.

\section{Materials and methods}

The study was performed on the basis of the pulmonology department of the Municipal Non-commercial Enterprise «City Clinical Hospital No. 13» of Kharkiv City Council (Kharkiv, Ukraine) during 2018-2019. We selected for participating in the study 100 patients (48 men and 52 women) with $\mathrm{ACO}$ and concomitant $\mathrm{AH}$.

Inclusion criteria for the study: age 45-65 years (54.38 44.57 years; the presence of ACO according to the criteria recommended by the joint GINA and GOLD document on diagnosis of bronchial obstructive diseases from 2017 [3], the criteria of the American Thorax Society (ATS) [10] and the criteria of the Spanish recommendations for bronchopulmonary diseases [11].

The diagnosis was based on the presence of all 3 major criteria and at least 1 minor criterion. The major criteria included: permanent airflow obstruction, age of the patient $\geq 40$ years, smoking $>10$ years or the equivalent of air pollution, as well as documented history of asthma up to 40 years or bronchial obstruction reversibility (BOR) $>400 \mathrm{ml}$; minor criteria: a documented history of atopy or allergic rhinitis, 2 separate BOR tests $>12 \%$ or $200 \mathrm{ml}$, and a blood eosinophil count 
of $\geq 300 / \mu 1$. We selected 2 degree by GOLD (50-80 \%) of airflow obstruction. Patients with stage II controlled AH were included in the study, whose diagnosis was determined according to the commonly accepted classification of blood pressure (BP) levels (as recommended by ESH/ESC) [12].

Exclusion criteria were obesity, diabetes mellitus, chronic infectious, systemic, oncological and psychiatric diseases, chronic heart failure with a left ventricular ejection fraction of less than $55 \%$, the presence of a history of myocardial infarction, stroke and signs of ischemic heart disease, heart valve regurgitation more than 2 degree.

Examination of the patients included: clinical methods - analysis of complaints and medical history of patients, standard clinical examination with measurement of BP and heart rate (HR), anthropometric study with determination of body mass index (BMI), spirometry with BOR with inhalation of $400 \mathrm{mcg}$ of salbutamol using the computer system "SPIROLAB" (manufactured by KhAI-Medika Research Institute in Kharkiv) according to the recommendations of ATS/ERS [13]. Shortness of breath was assessed by the Modified Medical Research Council Dyspnoea Scale (mMRS) [14], a comprehensive assessment of the severity of clinical symptoms was performed with COPD Assessment Test (CAT) [15], to assess the quality of life was used the questionnaire St. George's Respiratory Questionnaire (SGRQ) [16]. Functional status analysis included performing the 6MWT according to ATS recommendations [17].

The study was conducted in accordance with the requirements of the GCP, the Council of Europe Convention on Human Rights and Biomedicine, the Helsinki Declaration of the World Medical Association and was approved by a local ethics committee of Kharkov Medical Academy of Postgraduate Education (protocol No. 5, from 12 Nov 2019). All patients signed informed consent for participating in the clinical trial.

Patients were randomly divided into 2 groups of 50 patients who did not differ significantly in age, gender, smoking status, and BMI. All patients received triple therapy in stable dosage: inhaled corticosteroid, prolonged $\beta 2$ agonist and prolonged anticholinergic drug according to GINA / GOLD recommendations [3]. In addition to basic therapy, patients in the first group were provided with a rehabilitation program, recommended by GOLD, which included: an educational program (smoking cessation, correct use of inhaler devices, early recognition of exacerbation, decision-making and taking action, and when to seek help), the formation of self-management skills (goals of motivating, engaging and supporting the patients to positively adapt their health behavior(s) and develop skills to better manage their disease), a program of complex physical rehabilitation (strength training and aerobic training, upper extremities exercise training, inspiratory muscle training and metered walking) [18]. At the baseline all patients were assessed for spirometry with BOR test, BP and HR measurment, exercise tolerance by using 6MWT. This program was monitored on a weekly visit. The re-evaluation was performed after 16 weeks of comprehensive treatment. The examination was carried out during a period of remission characterized by stable clinical symptoms and indicators of respiratory function.

The obtained data were processed using the Statistic application. Quantitative data are presented as mean values (M) and standard deviations (SD). To describe qualitative variation, we used the frequency at which the traits were assessed in the group. The critical significance level of statistical significance at the null hypothesis test was assumed to be 0.05 . Parametric and non-parametric methods were used to compare the central parameters of the groups: Student's t-test, Wilcoxon tests (W) and Mann-Whitney (MU). The pairwise comparison of groups used the criterion U Mann-Whitney (MU), to compare the occurrence of a feature in the frequency analysis in groups used the Pearson test $\chi$-square $\left(\chi^{2}\right)$.

\section{Results}

The initial clinical and functional characteristics of the patients are presented in Table $\mathbf{1}$. The average age of the examined patients was $54.38 \pm 4.57$ years. Patients had extensive smoking experience $(29.82 \pm 6.22$ packs) and were active smokers (70 patients) or smokers in the past (30 patients). All examined patients had a normal body weight (BMI of $25.15 \pm 2.12 \mathrm{~kg} / \mathrm{m}^{2}$ ). Patients in both groups did not differ significantly in sex, smoking status, BP, HR, and BMI. 
Table 1

Clinical and functional characteristics of patients

\begin{tabular}{cccc}
\hline \multirow{2}{*}{ Indicators } & \multicolumn{1}{c}{ ACO with AH, $\mathbf{n = 1 0 0}$} \\
\cline { 2 - 3 } & Group 1 & Group 2 & P>0,05 \\
\cline { 2 - 4 } & $\mathbf{n}=\mathbf{5 0}$ & $\mathbf{n = 5 0}$ & 0.103 \\
Age, years & $53.62 \pm 4.18$ & $55.14 \pm \mathbf{0} .01$ & 0.842 \\
Gender, women/men & $26(52 \%) / 24(48 \%)$ & $25(50 \%) / 25(50 \%)$ & 0.663 \\
Smoking status, smokers/smokers in the past & $34(68 \%) / 16(32 \%)$ & $36(72 \%) / 14(28 \%)$ & 0.163 \\
Smoking experience, pack/years & $30.42 \pm 6.08$ & $28.86 \pm 4.98$ & 0.329 \\
BMI, $\mathrm{kg} / \mathrm{m}^{2}$ & $25.92 \pm 7.19$ & $24.42 \pm 8.08$ & 0.496 \\
Systolic BP, $\mathrm{mm} \mathrm{Hg}$ & $136.16 \pm 9.15$ & $134.84 \pm 10.12$ & 0.138 \\
Diastolic BP, $\mathrm{mm} \mathrm{Hg}$ & $82.43 \pm 8.48$ & $85.36 \pm 10.95$ & 0.202
\end{tabular}

There was also no discrepancy between the baseline condition of patients in both groups in spirometry results and quality of life.

A re-evaluation of spirometry after 16 weeks of treatment there were no changes in lung functional status in patients on standard treatment (group 2). At the same time, in the context of complex treatment in patients who had an active rehabilitation program (group 1), there was a significant improvement in the bronchial response to the action of bronchodilators $(\mathrm{p}=0.033)$, although other indicators of the functional status of the lungs did not show significant changes (Tables 2, 3).

Table 2

Assessment of spirometry, quality of life and functional status of patients against standard treatment and rehabilitation programs

\begin{tabular}{cccc}
\hline \multirow{2}{*}{ Indicators } & \multicolumn{2}{c}{ Group 1, n=50 } & p \\
\cline { 2 - 3 } & Baseline & After treatment & 0.140 \\
\hline FEV 1, \% of predicted & $64.12 \pm 13.82$ & $68.38 \pm 14.83$ & 0.129 \\
FEV 1/ FVC, \% & $64.27 \pm 5.68$ & $66.21 \pm 6.94$ & 0.526 \\
FEF 25, \% of predicted & $25.16 \pm 16.91$ & $27.35 \pm 17.46$ & 0.014 \\
FEF 50, \% of predicted & $23.91 \pm 9.67$ & $28.57 \pm 8.83$ & 0.625 \\
FEF 75, \% of predicted & $28.92 \pm 12.82$ & $30.26 \pm 14.42$ & 0.203 \\
FVC, \% of predicted & $77.45 \pm 14.94$ & $81.46 \pm 16.29$ & 0.033 \\
Reversibility after bronchodilator inhalation, \% & $18.05 \pm 5.63$ & $20.12 \pm 3.78$ & 0.012 \\
CAT, points & $18.86 \pm 7.26$ & $15.36 \pm 6.38$ & 0.018 \\
SMRC, points & $2.23 \pm 0.62$ & $1.84 \pm 0.86$ & 0.010
\end{tabular}

The quality of life scores varied significantly between groups. There were no significant changes in quality of life in standard-treated patients (Table 3). At the same time, patients who additionally used an active rehabilitation program had a significant improvement in clinical symptoms, shortness of breath, and quality of life according to CAT, mMRC, and SGRQ scores, respectively (Table 2). There was also a significant increase in distance during the 6MWT in Group 1. 
Table 3

Assessment of spirometry, quality of life and functional status of patients against standard treatment in patients

\begin{tabular}{cccc}
\hline Indicators & \multicolumn{2}{c}{ Group 2, $\mathbf{n}=\mathbf{5 0}$} & p \\
\cline { 2 - 3 } FEV 1, \% of predicted & Baseline & After treatment & 0.927 \\
FEV 1/ FVC, \% & $63.96 \pm 12.62$ & $64.21 \pm 14.55$ & 0.473 \\
FEF 25, \% of predicted & $63.72 \pm 5.48$ & $62.87 \pm 6.28$ & 0.870 \\
FEF 50, \% of predicted & $25.51 \pm 9.94$ & $25.82 \pm 8.86$ & 0.784 \\
FEF 75, \% of predicted & $24.56 \pm 6.34$ & $24.94 \pm 7.45$ & 0.918 \\
FVC, \% of predicted & $28.76 \pm 11.22$ & $29.02 \pm 13.81$ & 0.622 \\
Reversibility after bronchodilator inhalation, \% & $17.56 \pm 6.23$ & $75.84 \pm 15.27$ & 0.945 \\
CAT, points & $19.06 \pm 8.04$ & $17.64 \pm 5.27$ & 0.912 \\
mMRC, points & $2.18 \pm 0.58$ & $18.89 \pm 7.25$ & 0.361 \\
SGRC, points & $40.68 \pm 14.83$ & $2.06 \pm 0.72$ & 0.722
\end{tabular}

\section{Discussion}

Patients with ACO have severe manifestations. The use of all medicines included in the standard of treatment of these group patients, unfortunately, have limited potential to influence the organic changes in the lungs, which determine the functional parameters of spirometry.

AH may have an additional negative effect on functional status and quality of life on this group of patients. The B. Ding and M. Small study showed a significantly higher rate of concomitant cardiac comorbidity, including AH in COPD and ACO patients, compared to asthma alone [19], the same results were obtained by DJ Maselli et al [20], but these studies did not investigate the influence of concomitant $\mathrm{AH}$ on the course of ACO regarding quality of life, functional status.

A number of studies have found significantly higher levels of symptoms and exacerbations, decreased quality of life $[8,20]$ and functional status of patients with ACO $[9,21,22]$, however, studies have not analyzed the association of complaints, clinical, and functional status with concomitant pathology of patients.

Some studies have aimed to find ways that can improve the quality of life and functionality in patients with ACO on the background of basic drug therapy. A. Rodrigues et al, when investigating the effectiveness of a 12-week training program in patients with ACO compared patients with COPD, received improvements in pulmonary function, 6MWT, peripheral and inspiratory muscle strength, SGRQ, however, no significant difference was found in the results of the two groups, as well as differences in $6 \mathrm{MWT}$ and mMRC in the dynamics of treatment $[23,24]$. The fatigue of our study showed that conducting an active rehabilitation program (physical rehabilitation in combination with an educational program) in patients with ACO with concomitant AH significantly improves the bronchial response to the action of bronchodilators by spirometry test, reduces the clinical manifestation and exercise tolerance, according to CAT, mMRC, SGRQ, and 6MWT questionnaires, respectively.

The limitations of the research. The present study was intended to investigate only the functional status and quality of life ACO patients with concomitant AH and did not include analysis of clinical and laboratory parameters for these patient groups, as well as the study of patients with other chronic respiratory diseases and variants of comorbidity. 
The further research plan includes the study of clinical and laboratory status in patients with $\mathrm{ACO}$ with concomitant $\mathrm{AH}$, analysis $\mathrm{BP}, \mathrm{HR}$, saturation rates in dynamics of complex therapy in ACO with AH group of patients.

\section{Conclusions}

Conducting an active rehabilitation program (physical rehabilitation in combination with an educational program and self-management) in group of patients with ACO and concomitant AH, who are on standard medical treatment, significantly improves the bronchial response to the action of bronchodilators, decreases clinical manifestations, shortness of breath and improve quality of life and exercise tolerance, according to CAT, mMRC, SGRQ and 6MWT questionnaires, respectively.

\section{Conflicts of interest}

No conflict of interest.

\section{References}

[1] Burney, P., Jarvis, D., Perez-Padilla, R. (2015). The global burden of chronic respiratory disease in adults. The International Journal of Tuberculosis and Lung Disease, 19 (1), 10-20. doi: http://doi.org/10.5588/ijtld.14.0446

[2] Kumbhare, S., Pleasants, R., Ohar, J. A., Strange, C. (2016). Characteristics and Prevalence of Asthma/Chronic Obstructive Pulmonary Disease Overlap in the United States. Annals of the American Thoracic Society, 13 (6), 803-810. doi: http:/doi.org/ 10.1513/annalsats.201508-554oc

[3] Diagnosis and Initial Treatment of Asthma COPD and Asthma (2017). Available at: https://ginasthma.org/wp-content/uploads/2019/11/GINA-GOLD-2017-overlap-pocket-guide-wms-2017-ACO.pdf

[4] Diagnosis of Diseases of Chronic Air ow Limitation: Asthma, COPD and Asthma-COPD Overlap Syndrome (ACOS). (2014). Available at: https://www.sogapar.info/wp-content/uploads/2016/12/9.-ACOS-Gold-Gina.pdf

[5] Yeh, J.-J., Wei, Y.-F., Lin, C.-L., Hsu, W.-H. (2017). Association of asthma-chronic obstructive pulmonary disease overlap syndrome with coronary artery disease, cardiac dysrhythmia and heart failure: a population-based retrospective cohort study. BMJ Open, 7 (10), e017657. doi: http://doi.org/10.1136/bmjopen-2017-017657

[6] Bujarski, S., Parulekar, A. D., Sharafkhaneh, A., Hanania, N. A. (2015). The Asthma COPD Overlap Syndrome (ACOS). Current Allergy and Asthma Reports, 15 (3). doi: http://doi.org/10.1007/s11882-014-0509-6

[7] Gerhardsson de Verdier, M., Andersson, M., Kern, D. M., Zhou, S., Tunceli, O. (2015). Asthma and Chronic Obstructive Pulmonary Disease Overlap Syndrome: Doubled Costs Compared with Patients with Asthma Alone. Value in Health, 18 (6), 759-766. doi: http://doi.org/10.1016/j.jval.2015.04.010

[8] Kauppi, P., Kupiainen, H., Lindqvist, A., Tammilehto, L., Kilpeläinen, M., Kinnula, V. L. et. al. (2011). Overlap Syndrome of Asthma and COPD Predicts Low Quality of Life. Journal of Asthma, 48 (3), 279-285. doi: http://doi.org/10.3109/02770903.2 011.555576

[9] Fu, J., Gibson, P. G., Simpson, J. L., McDonald, V. M. (2014). Longitudinal Changes in Clinical Outcomes in Older Patients with Asthma, COPD and Asthma-COPD Overlap Syndrome. Respiration, 87 (1), 63-74. doi: http://doi.org/10.1159/000352053

[10] Woodruff, P. G., van den Berge, M., Boucher, R. C., Brightling, C., Burchard, E. G., Christenson, S. A. et. al. (2017). American Thoracic Society/National Heart, Lung, and Blood Institute Asthma-Chronic Obstructive Pulmonary Disease Overlap Workshop Report. American Journal of Respiratory and Critical Care Medicine, 196 (3), 375-381. doi: http://doi.org/10.1164/ rccm.201705-0973ws

[11] Miravitlles, M., Alvarez-Gutierrez, F. J., Calle, M., Casanova, C., Cosio, B. G., López-Viña, A. et. al. (2017). Algorithm for identification of asthma-COPD overlap: consensus between the Spanish COPD and asthma guidelines. European Respiratory Journal, 49 (5), 1700068. doi: http://doi.org/10.1183/13993003.00068-2017

[12] $2018 \mathrm{ESC} / \mathrm{ESH}$ Guidelines for the management of arterial hypertension. (2019). Journal of Hypertension, 37 (1), 226. doi: http://doi.org/10.1097/hjh.0000000000002017

[13] ATS/ERS Recommendations for Standardized Procedures for the Online and Offline Measurement of Exhaled Lower Respiratory Nitric Oxide and Nasal Nitric Oxide, 2005. (2005). American Journal of Respiratory and Critical Care Medicine, 171 (8), 912-930. doi: http://doi.org/10.1164/rccm.200406-710st

[14] mMRC (Modified Medical Research Council) Dyspnea Scale. Available at: https://www.mdcalc.com/mmrc-modifiedmedical-research-council-dyspnea-scale

[15] COPD Assessment Test. Available at: https://www.catestonline.org/

[16] St. George's Respiratory Questionnaire. Available at: http://www.healthstatus.sgul.ac.uk/sgrq 
[17] ATS Statement (2002). American Journal of Respiratory and Critical Care Medicine, 166 (1), 111-117. doi: http://doi.org/10.1164/ ajrccm.166.1.at1102

[18] Gold Reports for Personal Use - Global Initiative for Chronic Obstructive Lung Disease. Available at: https://goldcopd.org/ gold-reports/

[19] Ding, B., Small, M. (2017). Treatment trends in patients with asthma\&ndash;COPD overlap syndrome in a COPD cohort: findings from a real-world survey. International Journal of Chronic Obstructive Pulmonary Disease, 12, 1753-1763. doi: http:// doi.org/10.2147/copd.s136314

[20] Maselli, D. J., Hanania, N. A. (2018). Asthma COPD overlap: Impact of associated comorbidities. Pulmonary Pharmacology \& Therapeutics, 52, 27-31. doi: http://doi.org/10.1016/j.pupt.2018.08.006

[21] Alshabanat, A., Zafari, Z., Albanyan, O., Dairi, M., FitzGerald, J. M. (2015). Asthma and COPD Overlap Syndrome (ACOS): A Systematic Review and Meta Analysis. PLOS ONE, 10 (9), e0136065. doi: http://doi.org/10.1371/journal.pone. 0136065

[22] Cosentino, J., Zhao, H., Hardin, M., Hersh, C. P., Crapo, J., Kim, V., Criner, G. J. (2016). Analysis of Asthma-Chronic Obstructive Pulmonary Disease Overlap Syndrome Defined on the Basis of Bronchodilator Response and Degree of Emphysema. Annals of the American Thoracic Society, 13 (9), 1483-1489. doi: http://doi.org/10.1513/annalsats.201511-761oc

[23] Global Initiative for Asthma (2014). Diagnosis of diseases of chronic airflow limitation: asthma, COPD, and asthma-COPD overlap syndrome (ACOS). Available at: www.ginasthma.org

[24] Rodrigues, A., de Oliveira, J. M., Furlanetto, K. C., Machado, F. V. C., Belo, L. F., Schneider, L. P. et. al. (2019). Are the Effects of High-Intensity Exercise Training Different in Patients with COPD Versus COPD+Asthma Overlap? Lung. doi: http:/doi.org/ 10.1007/s00408-019-00311-7

\title{
PECULIARITIES OF STATE OF PROTECTION AND AGGRESSION FACTORS IN PATIENTS WITH DIABETES MELLITUS TYPE II AND GASTROESOPHAGEAL REFLUX DISEASE
}

\author{
Aleksey Oparin
}

Anton Kudriavtsev

Anatoliy Oparin ${ }^{1}$

${ }^{1}$ Department of Therapy, Rheumatology and Clinical Pharmacology

Kharkiv Medical Academy of Postgraduate Education

58 Amosova str., Kharkiv, Ukraine, 61176

\begin{abstract}
Diabetes mellitus is one of the most serious problems of the clinical medicine. This is determined by the fact that it is followed by multisystemic affects, as well as complications on the side of other organs and systems, among which a special place is occupied by gastroesophageal reflux disease. As for the combination and mutual influence of diabetes mellitus and gastroesophageal reflux disease, this issue has not been studied yet, the data of modern literature are not complete and quite contradictory.

The aim of the study: to investigate the state of the factors of aggression and protection of the oesophageal mucosa in patients with diabetes mellitus type II with concomitant gastroesophageal reflux disease without associated pathology.

Method. There were two groups of patients under observation. The first group included 45 patients with diabetes mellitus type II with concomitant gastroesophageal reflux disease ( 26 men and 19 women). The second group included 38 patients with gastroesoph-
\end{abstract}

